\title{
Adrenal insufficiency causes life-threatening arrhythmia with prolongation of QT interval
}

\author{
Jin Komuro ${ }^{1}$ Mitsunobu Kaneko ${ }^{1} \cdot$ Kazutaka Ueda $^{1} \cdot$ Shuya Nitta $^{1} \cdot$ \\ Masashi Kasao $^{1} \cdot$ Tetsuro Shirai $^{1}$
}

Received: 12 October 2014 / Accepted: 6 March 2015 / Published online: 15 March 2015

(C) The Author(s) 2015. This article is published with open access at Springerlink.com

\begin{abstract}
A 63-year-old woman who had hypopituitarism was re-admitted to our hospital because of fever, diarrhea and disturbance of consciousness with life-threatening arrhythmia due to prolongation of the QT interval. She has been treated with hydrocortisone consequently, and has shown few ventricular arrhythmias with normalization of the QT interval. There have been several reports showing the case of prolonged QT interval with adrenal insufficiency, but there are few reports of isolated adrenocorticotropic hormone deficiency without any electrolytes imbalance that showed polymorphic ventricular tachycardia associated with QT prolongation. We discuss some possible mechanisms of how adrenal insufficiency causes life-threatening arrhythmia. Since lack of glucocorticoid hormone might induce prolongation of the QT interval, patients with adrenal insufficiency should be paid attention as candidates of lethal arrhythmias particularly when exposed to excessive stresses.
\end{abstract}

Keywords Polymorphic ventricular tachycardia . Hypopituitarism · Long-QT syndrome · Adrenal crisis · Serum- and glucocorticoid-inducible kinase (SGK1)

\section{Introduction}

Adrenal crisis is a life-threatening emergency, however, the relation between adrenal crisis and life-threatening

Jin Komuro

sieg_erringen@yahoo.co.jp

1 Department of Cardiology, Tokyo Metropolitan Police Hospital, 4-22-1 Nakano-ku, Nakano, Tokyo 164-8541, Japan arrhythmia is not known. We describe a case with adrenal crisis and polymorphic ventricular tachycardia (VT).

\section{Case report}

A 63-year-old woman was re-admitted to our hospital because of fever, diarrhea and disturbance of consciousness with polymorphic VT. She had been first admitted to our hospital five years ago because of polymorphic VT (Fig. 1). Serum concentrations of cortisol, luteinizing hormone, follicle stimulating hormone, and prolactin had been very low with relatively low concentrations of corticotropin, while those of thyroid hormone and serum electrolytes levels had been almost normal. She had had a history of large bleeding by extrauterine pregnancy and her brain MRI had shown atrophy of pituitary, suggesting that her hypopituitarism was due to Sheehan's syndrome [1]. She has no family history of VT and sudden deaths. On admission of this time, she had fever $\left(38.0{ }^{\circ} \mathrm{C}\right)$ with slightly lower blood pressure $(92 / 60 \mathrm{mmHg})$. Her ECG showed prolongation of the QT interval (QTc $567 \mathrm{~ms}$ ) (Fig. 2a) and ECG monitor recorded various arrhythmias such as sinus bradycardia, atrial flutter, paroxysmal atrial fibrillation, and polymorphic VT. Routine blood examination revealed normal levels of sodium $(137 \mathrm{mEq} / \mathrm{L})$, potassium $(3.8 \mathrm{mEq} / \mathrm{L})$, and calcium $(9.9 \mathrm{mg} / \mathrm{dl})$, and slightly high levels of magnesium $(2.75 \mathrm{mg} / \mathrm{dl})$. C-reactive protein and white blood cell counts were elevated $6.9 \mathrm{mg} / \mathrm{dl}$ and $11 \times 10^{3} \mu \mathrm{l}$, respectively. The rapid test of influenza type A was positive. Ultrasound echocardiography (UCG) showed normal cardiac size and function of the left ventricle. We intravenously administered hydrocortisone with large volume of physiological saline and started rapid ventricular pacing at the rate of $120 \mathrm{bpm}$. In the second day of the treatments, 

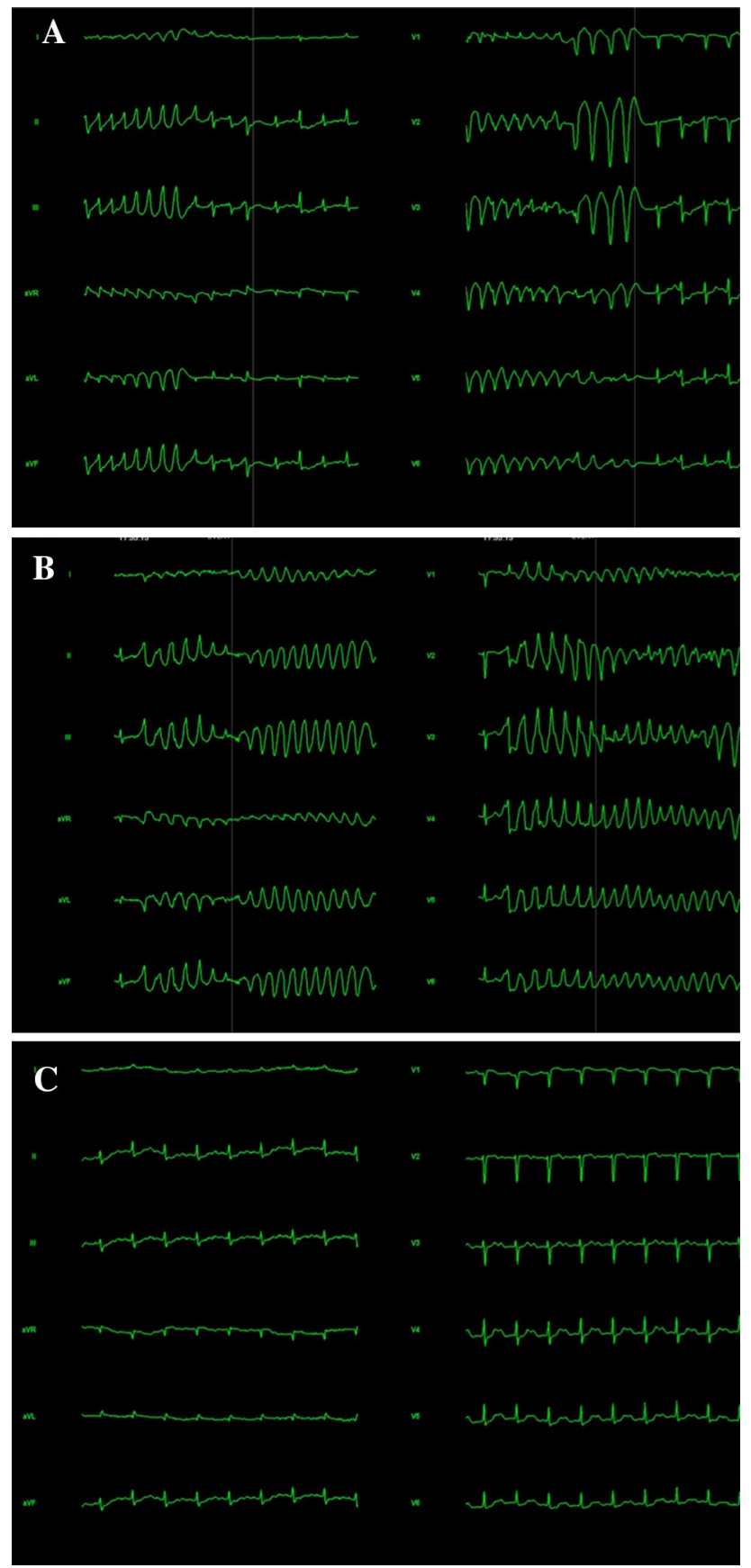

Fig. 1 Polymorphic ventricular tachycardia recorded in 2009. a Short-long-short pattern of R-R cycles just before the occurrence of Torsades de Pointes. b Torsades de Pointes. c QT prolongation

arrhythmias were not observed and the QT interval was normalized (QTc $394 \mathrm{~ms}$ ) (Fig. 2b).

Although she has been treated with hydrocortisone for secondary adrenal insufficiency due to hypopituitarism, adrenal crisis might be induced by infection of influenza. When she arrived at our hospital, the QT interval was remarkably prolonged, however, it became normal within $12 \mathrm{~h}$ with replacement of glucocorticoids.
A

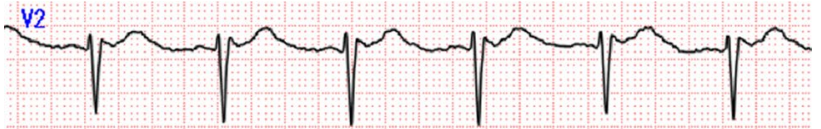<smiles>CCCCC(C)CCCC(C)(C)CCC(C)CCC(C)CCC(C)(C)CC</smiles>
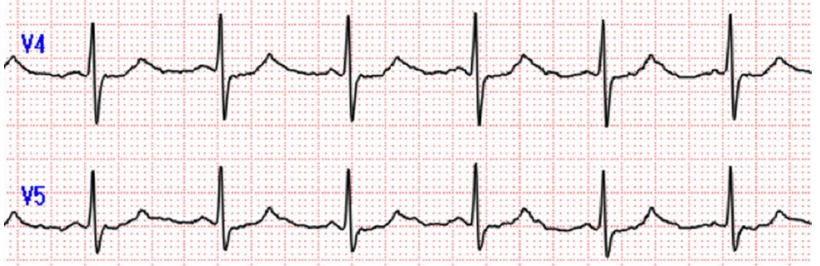

\section{B}

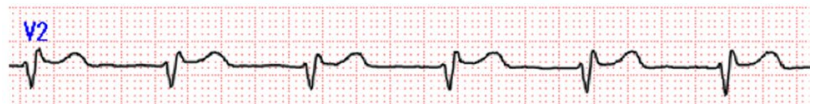

Y3
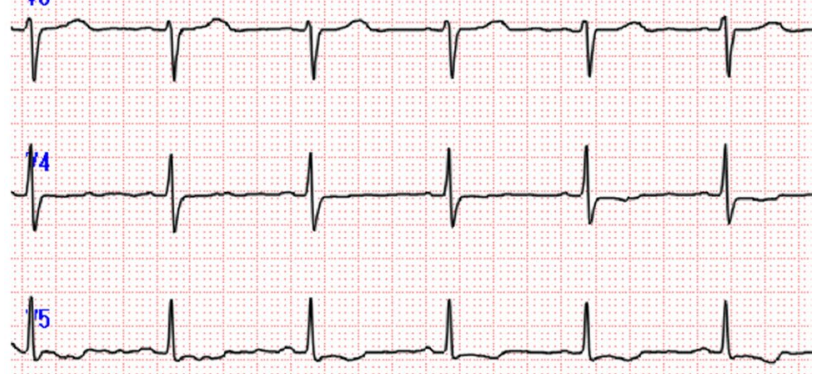

Fig. 2 QT interval before and after administration of hydrocortisone. a Prolongation of the QT interval on admission. QTc, $521 \mathrm{~ms}$. b Normalized QT interval after administration of hydrocortisone. QTc, $433 \mathrm{~ms}$. QTc was measured at lead V5

\section{Discussion}

It is well known that hypothyroidism causes QT prolongation [2], but her serum concentrations of thyroid hormone had been almost normal from the first visit. On the other hand, her serum concentration of cortisol was very low $(0.4 \mu \mathrm{g} / \mathrm{dl})$ just before hospitalization and replacement of glucocorticoids promptly normalized the QT interval, suggesting that prolongation of the QT interval is due to lack of glucocorticoid hormone. There have been several reports showing the cases of prolonged QT interval with adrenal insufficiency. Previous reports described cases of Torsade de Pointes associated with hypopituitarism which were treated with steroid and thyroid hormone [6-8]. Other reports described cases of Torsade de Pointes associated with hypopituitarism and electrolytes imbalance [7, 8]. A case of adrenal insufficiency with severe hypokinesis of left ventricle and $\mathrm{T}$ wave inversion at ECG was also reported [7]. There are few reports of isolated adrenocorticotropic 
hormone deficiency without any electrolytes imbalance that showed polymorphic VT associated with QT prolongation [3]. In our case, the abnormality was only concentrations of cortisol and there were no electrolytes imbalance, hypothyroidism, or hypokinesis of the left ventricle. Although precise mechanisms of QT prolongation by glucocorticoid insufficiency are not known, there are some possibilities. Glucocorticoid has been reported to be important for the maintenance of membrane calcium transport function in the cardiac sarcoplasmic reticulum [3]. It has been also reported that glucocorticoid up-regulates expression levels of various ion channels, including $\mathrm{I}_{\mathrm{Ks}}$ (mink, KvLQT1), and $\mathrm{I}_{\mathrm{Kr}}$ (hERG, MiRP1) by inducing expressions of the serum- and glucocorticoid-inducible kinase (SGK1) [4]. Since these $\mathrm{I}_{\mathrm{K}}$ channels induce outward potassium currents, lack of glucocorticoid may extend duration of action potentials by reducing expressions of SGK1 and these ion channels [5]. In fact, there is a report showing that mutations in the hERG gene cause congenital long-QT syndrome [9].

Long-QT syndrome causes life-threatening ventricular arrhythmias such as Torsades de Pointes. Since lack of glucocorticoid hormone might induce prolongation of the QT interval, patients with adrenal insufficiency should be paid attention as candidates of lethal arrhythmias particularly when exposed to excessive stresses.

This study has been performed in accordance with the ethical standards laid down in the 1964 Declaration of Helsinki and its later amendments. We have obtained the informed consent from the patient.

Conflict of interest The authors declare that they have no conflict of interest.
Open Access This article is distributed under the terms of the Creative Commons Attribution License which permits any use, distribution, and reproduction in any medium, provided the original author(s) and the source are credited.

\section{References}

1. Charmandari E, Nicolaides N, Chrousos G (2014) Adrenal insufficiency. Lancet 383:2152-2167

2. Lane JD, Keenan NG, Bouloux P, Rogers D (2012) A heart without hormones. Lancet 379:1922

3. Nishizawa S, Nakamura T, Hamaoka T, Matsumuro A, Sawada T, Matsubara H (2009) Lethal arrhythmia and corticosteroid insufficiency. Am J Emerg Med 27: 1167.e1-1167.e3

4. Lang F, Shumilina E (2013) Regulation of ion channels by the serum- and glucocorticoid-inducible kinase SGK1. FASEB J 27:3-12

5. Lamothe SM, Zhang S (2013) The Serum- and Glucocorticoidinducible Kinase SGK1 and SGK3 Regulate hERG Channel Expression via Ubiquitin Ligase Nedd4-2 and GTPase Rab 11. J Biol Chem 288:15075-15084

6. Kim HN, Cho GJ, Ahn KY, Lee US, Kim HK, Cho HJ, Kim GH, Kim W, Jeong HM, Park CJ, Kang CJ (2001) A case of Torsade de Pointes associated with hypopituitarism due to hemorrhagic fever with renal syndrome. J Korean Med Sci 16:355-358

7. Kanamori K, Yamashita R, Tsutsui K, Hara M, Murakawa Y (2014) Long QT syndrome associated with adrenal insufficiency in a patient with isolated adrenocorticotropic hormone deficiency. Intern Med 53:2329-2331

8. Kang GD, Kim ES, Park SM, Kim JE, Lee HJ, Park GD, Han RK, Oh JD (2013) Acquired long QT syndrome manifesting with Torsades de Pointes in a patient with panhypopituitarism due to radiotherapy. Korean Circ J 43:340-342

9. Bando S, Soeki T, Matsuura T, Niki T, Ise T, Yamaguchi K, Taketani Y, Iwase T, Yamada H, Wakatsuki T, Akaike M, Aiba T, Shimizu W, Sata M (2014) Congenital long QT syndrome with compound mutations in the KCNH2 gene. Heart Vessel 29:554-559 